\title{
Simplified approach to characterize anisotropic strength of granular soils
}

\author{
Quan Sun and Junxing Zheng ${ }^{*}$ (D)
}

\section{${ }^{*}$ Correspondence:}

junxing@iastate.edu Department of Civil,

Construction

and Environmental

Engineering, lowa State

University, Ames, IA 50011 USA

\begin{abstract}
Experimental evidence shows that the strength of granular soils is significantly influenced by inherent cross anisotropy which cannot be properly described by isotropic failure criteria. This paper reviewed laboratory test results of various sands at different fabric directions. Based on the observations, this paper formulates the hypothesis that deposit plane creates a plane of weakness and the anisotropic strength of sands depends on orientations of deposit plane and failure plane. The strength decreases when orientations of deposit plane and failure plane are close to each other, and the strength increase when they diverge from each other. Then, an anisotropic failure criterion is developed based on this hypothesis and validated by available experimental data from literature. Remarkable agreements between predictions and measurements have been observed, which demonstrate validity, effectiveness, and robustness of new criterion in characterizing anisotropic strength of sands with variations of loading directions and intermediate principal stresses.
\end{abstract}

Keywords: Fabric anisotropy, Granular soils, Anisotropic failure criterion, Laboratory tests, Mobilized plane

\section{Introduction}

A majority of geomaterials are inherently cross-anisotropic (or transverse isotropic) due to the depositional processes. The normal of deposit plane is usually called fabric direction. The cross-anisotropic structure of geomaterials features inhomogeneous shear responses which depend on relationship between loading and fabric directions. For example, Oda and Koishikawa [1] and more recently Azami et al. [2] both performed bearing capacity tests of a strip footing on sand and observed the bearing capacity in the fabric direction was $25-34 \%$ higher than the bearing capacity in the direction perpendicular to the fabric direction. The anisotropic strength of sands has been observed in laboratory tests by Oda [3-5], Oda et al. [6, 7], Arthur and Menzies [8], Arthur and Phillips [9], Wong and Arthur [10], Arthur et al. [11], Ochiai and Lade [12], Tatsuoka et al. [13], Lade et al. [14], Lam and Tatsuoka [15], and Yang et al. [16]. Such anisotropic strength cannot be described by isotropic failure criteria such as Mohr-Coulomb failure criterion, the Drucker-Prager failure criterion, and Lade's failure criterion [17]. Therefore, various anisotropic failure criteria have been developed. These anisotropic failure criteria can be divided into two categories.

(c) The Author(s) 2020. This article is licensed under a Creative Commons Attribution 4.0 International License, which permits use, sharing adaptation, distribution and reproduction in any medium or format, as long as you give appropriate credit to the original author(s) and the source, provide a link to the Creative Commons licence, and indicate if changes were made. The images or other third party material in this article are included in the article's Creative Commons licence, unless indicated otherwise in a credit line to the material. If material is not included in the article's Creative Commons licence and your intended use is not permitted by statutory regulation or exceeds the permitted use, you will need to obtain permission directly from the copyright holder. To view a copy of this licence, visit http://creativeco mmons.org/licenses/by/4.0/. 
The first strategy was to reuse existing isotropic failure criteria by rotating principal stresses. The isotropic failure criteria were developed by assuming coaxiality between loading direction and fabric direction. However, the non-coaxiality between loading direction and fabric direction induces the strength variance in cross-anisotropic soils which violated assumption of isotropic failure criteria. To overcome such non-coaxiality, researchers rotated principal stress space around origin so that the loading and fabric direction were coaxial again and the existing isotropic failure can be reused for cross-anisotropic soils, such as [18].

The second strategy was to use fabric tensors. The fabric tensors quantify the fabric structure formed in soils due to distributions of contact normals, voids, branch vectors, and particle long axes (Oda and Nakayama [19]). A popular fabric tensor was proposed by Oda and Nakayama [19], which was used by Li and Dafalias [20], Dafalias et al. [21], Gao et al. [22], and Gao and Zhao [23] to formulate their anisotropic failure criteria. The second fabric tensor, called microstructure tensor, was developed by Pietruszczak and Mroz [24, 25], which was used by Pietruszczak and Mroz [24, 25], Lade [26, 27], Schweiger et al. [28], and Kong et al. [29] to develop their anisotropic failure criteria.

The fabric direction $\mathbf{f}$ can be identified by two spherical coordinates $\vartheta$ and $\xi$ in principal stress space as shown in Fig. 1a. The $\vartheta$ is the angle between fabric direction $\mathbf{f}$ and major principal stress $\sigma_{1}$ and $\xi$ is the angle between fabric direction $\mathbf{f}$ and intermediate principal stress $\sigma_{2}$. Three common fabric configurations were investigated in the experimental studies: (1) $\mathbf{f}$ is perpendicular to $\sigma_{1}: \vartheta=90^{\circ}$ and $\xi=0-90^{\circ}$ (structure 1 in Fig. 1b); (2) f is perpendicular to $\sigma_{2}: \vartheta=0-90^{\circ}, \xi=90^{\circ}$ (structure 2 in Fig. 1c), and (3) f is perpendicular to $\sigma_{3}: \vartheta=0-90^{\circ}, \xi=0^{\circ}$ (structure 3 in Fig. 1d).

The existing anisotropic failure criteria focused on predicting anisotropic strength in structure 2 while the anisotropic strength in structures 1 and 3 are rarely studied. This study focuses on developing a generalized anisotropic failure criterion which can applied to three fabric configurations. The new anisotropic failure criterion will be formulated by integrating spatial mobilized plane developed by Nakai and Matsuoka $[30,31]$ and the isotropic failure criterion developed by Lade [17]. The new anisotropic failure criterion only required three parameters to calibrate but demonstrated excellent prediction accuracy.

\section{Anisotropic strength observations}

The strength variation of cross-anisotropic soil at structure 2 has been extensively studied by many researchers using symmetrical triaxial test, plane strain compression test and torsion shear test. Figure 2 displays the symmetrical triaxial testing results of

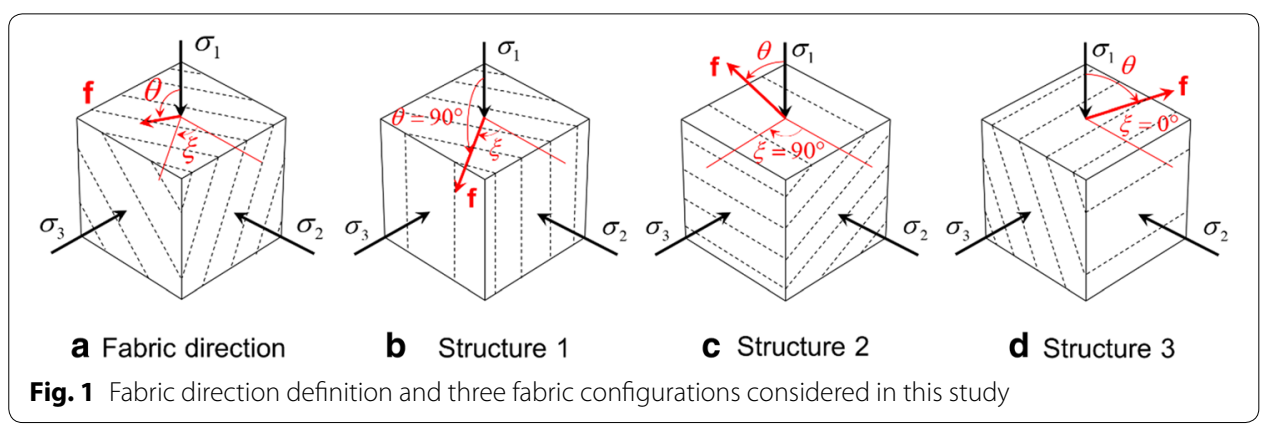


four different sands including Cambria sand from Ochiai and Lade [12], Leighton Buzzard sand from Arthur and Menzies [8], Ham river sand from Arthur and Phillips [9], and Toyoura sand from Oda [3]. The inclination angle $\vartheta$ was changed from $0^{\circ}$ to $90^{\circ}$ in the tests to investigate the anisotropic strength of sands. As shown, all the experimental results exhibited a similar trend that angles of internal friction $(\phi)$ monotonically decrease as $\vartheta$ increases from $0^{\circ}$ to $90^{\circ}$. The variation of $\phi$ values, defined as $\Delta \phi$, was about $3^{\circ}$.

Lade et al. [14] performed a series of torsion shear tests on Nevada sand under constant stress ratio $b(b=0,0.25,0.5,0.75,1.00)$ and constant mean effective stress $p^{\prime}=100 \mathrm{kPa}$ condition, where $b=\left(\sigma_{2}-\sigma_{3}\right) /\left(\sigma_{1}-\sigma_{3}\right)$ and $p^{\prime}=\left(\sigma_{1}+\sigma_{2}+\sigma_{3}\right) / 3$. The inclination angle $\vartheta$ was changed to investigate the anisotropic strength in structure 2 in Fig. 1. Their test configurations were essentially equivalent to true triaxial test condition. The $b=0$ tests were equivalent to symmetrical triaxial test, in which $\phi$ monotonically decreases as $\vartheta$ increases from $0^{\circ}$ to $90^{\circ}$ akin to the symmetrical triaxial tests. However, in $\mathrm{b}=0.25,0.5$ and 0.75 tests, the $\phi$ curves exhibited a "checkmark" shape as $\vartheta$ increases from $0^{\circ}$ to $90^{\circ}$. The maximum $\phi$ was at $\vartheta=0^{\circ}$ while the minimum $\phi$ was at $\vartheta=67.5^{\circ}$.

The $b=1$ tests were equivalent to triaxial extension test. The $\phi$ value at $\vartheta=67.5^{\circ}$ was somewhat abnormal and does not follow the checkmark shape as shown in Fig. 3a, which was likely attributed to test error as pointed out by [32]. Lam and Tatsuoka [15] and Yang et al. [16] reported that traxial extension test results still displayed a checkmark shape similar to $b=0.25,0.5$ and 0.75 tests. The range of $\phi$ values, $\Delta \phi$ values, were $6^{\circ}, 9^{\circ}, 13^{\circ}, 24^{\circ}$, and $18^{\circ}$ for $b=0,0.25,0.5,0.75$ and 1.0 respectively. That implied that stronger anisotropic strength responses occurred at higher $b$ values.

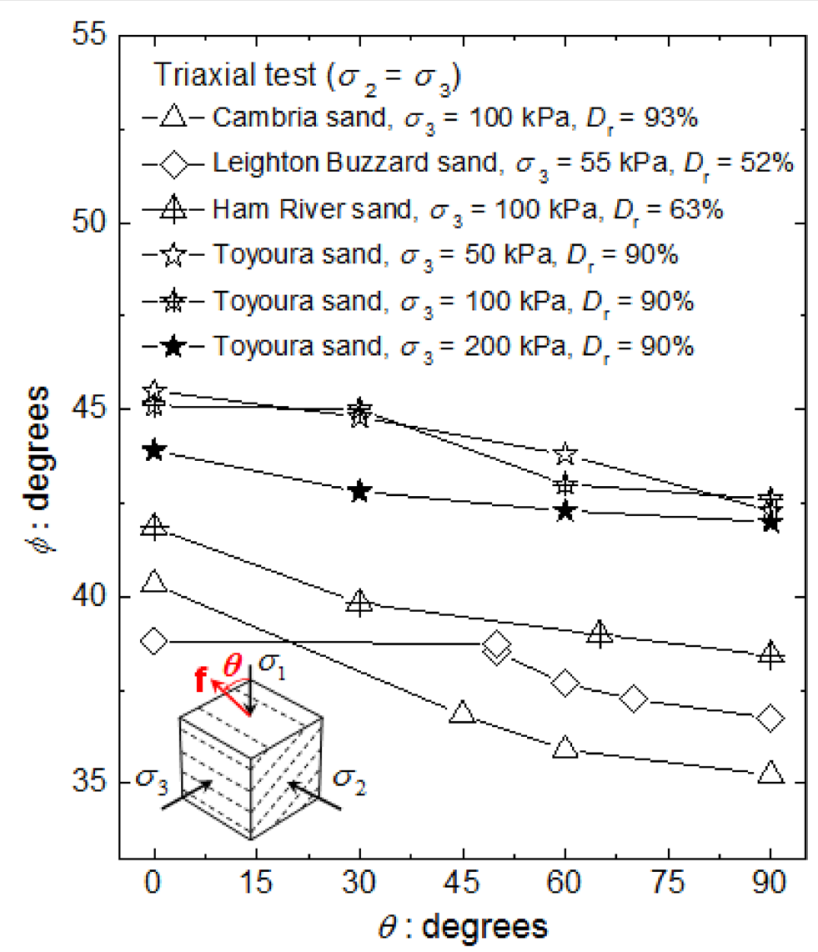

Fig. 2 Anisotropic strength of four sands in symmetrical triaxial tests 

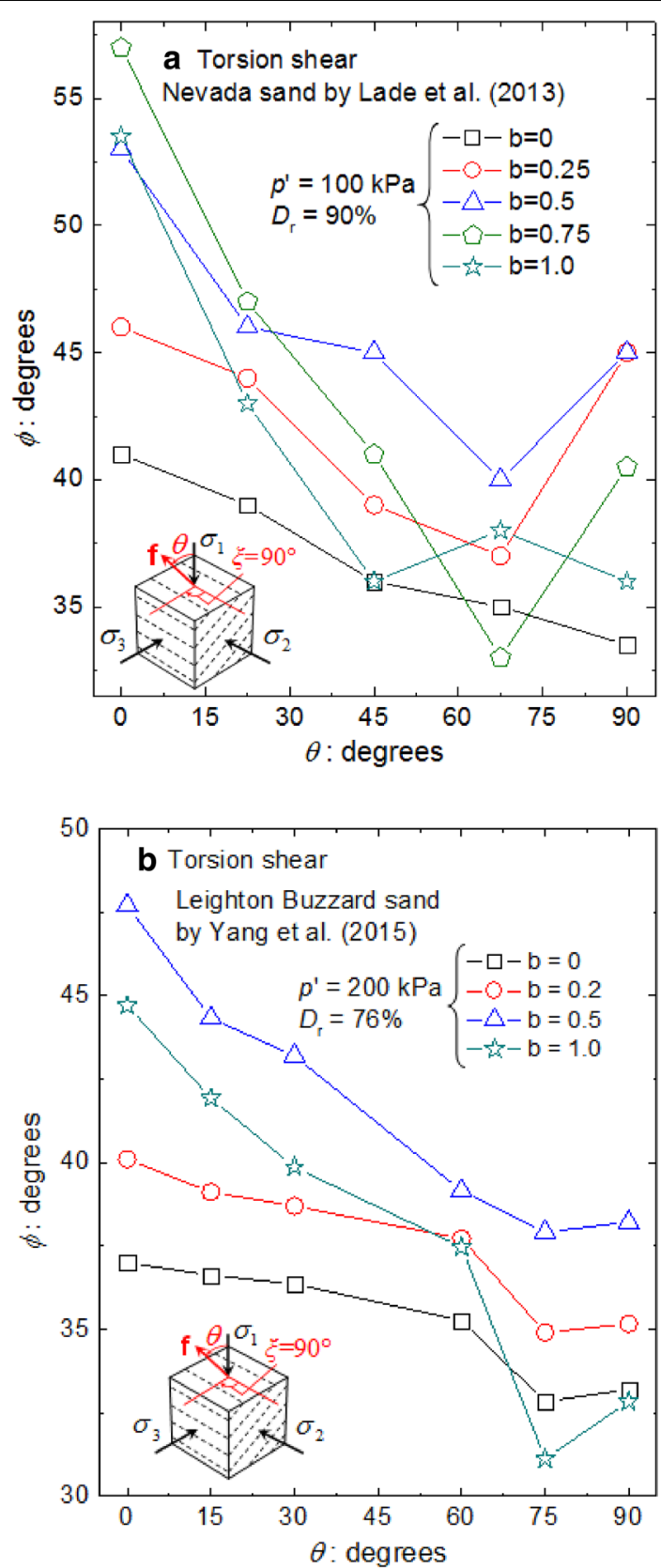

Fig. 3 Anisotropic strength of Nevada sand and Leighton Buzzard sand in torsion shear tests

Yang et al. [16] performed a series of torsion shear tests on Leighton Buzzard sand under the constant mean effective stress $p^{\prime}=200 \mathrm{kPa}$ and constant stress ratios $b=0$, $0.25,0.5,0.75$ and 1.0. The angle $\vartheta$ was changed from $0^{\circ}$ to $90^{\circ}$ while fabric normal $\mathbf{f}$ was kept parallel to the direction of intermediate stress $\sigma_{2}\left(\xi=90^{\circ}\right)$. The relative density $D_{\mathrm{r}}$ was set as $76 \%$ for all the tests. The results were presented in Fig. 3b. The $\phi$ values displayed checkmark shapes for all the tests. The minimum $\phi$ values occurred at $\vartheta=75^{\circ}$. The $\Delta \phi$ values were $4.3^{\circ}, 5.5^{\circ}, 9.8^{\circ}$, and $13.5^{\circ}$ for $b=0,0.2,0.5$ and 1.0 respectively. 
This agreed with Lade et al's [14] results that stronger anisotropic strength responses occurred at higher $b$ values.

A series of plane strain compression tests on Toyoura sand at various confining stresses and relative densities were performed by Tatsuoka et al. [13] as shown in Fig. 4. The specimen was cubical shape and the intermediate principal strain was restricted to create a plane strain testing condition. The $\vartheta$ was changed from $0^{\circ}$ to $90^{\circ}$ while the $\xi$ was kept as $90^{\circ}$ (structure 2 in Fig. 1c). The $\phi$ curves at both dense $\left(D_{\mathrm{r}}=80-91 \%\right)$ and medium dense $\left(D_{\mathrm{r}}=50-60 \%\right)$ conditions displayed a checkmark shape as shown in Fig. 4. The minimum $\phi$ values occurred at $\vartheta=56^{\circ}-67^{\circ}$ and the maximum $\phi$ values were at $\vartheta=0^{\circ}$. As will be shown later, the $b$ values in the plane strain test were in a range of 0.2 to 0.3 , so the plane strain test results should be close to $b=0.25$ triaxial tests.

Theoretically, larger confining stresses would depress anisotropic responses, resulting in flatter checkmark shape curves. However, checkmarks of $5 \mathrm{kPa}$ and $400 \mathrm{kPa}$ at the same density demonstrated the similar slopes, which implied the confining stresses smaller than $400 \mathrm{kPa}$ had limited effects on anisotropic responses of sands. However, checkmarks at dense condition were clearly steeper than checkmarks in the medium dense condition. The $\Delta \phi$ was about $8^{\circ}$ for dense condition while $\Delta \phi$ was about $4^{\circ}$ for medium dense condition. Therefore, the stronger fabric anisotropy occurred at higher relative density $D_{\mathrm{r}}$. This observation agree with Zheng and Hryciw [33, 34]. Anisotropic strength of sands for $\sigma_{3}>400 \mathrm{kPa}$ and $D_{\mathrm{r}}<50 \%$ are not clear because of no experimental data available.

The degrees of fabric anisotropy in soil also depend on alignment of particle long axes and particle shapes. The elongated soils tend to develop stronger fabric anisotropy [34]. To investigate such effects, Oda [5] performed plane strain compression tests on three specimens at dense state under $\sigma_{3}=200 \mathrm{kPa}$ : Toyoura sand with cross anisotropic fabric,

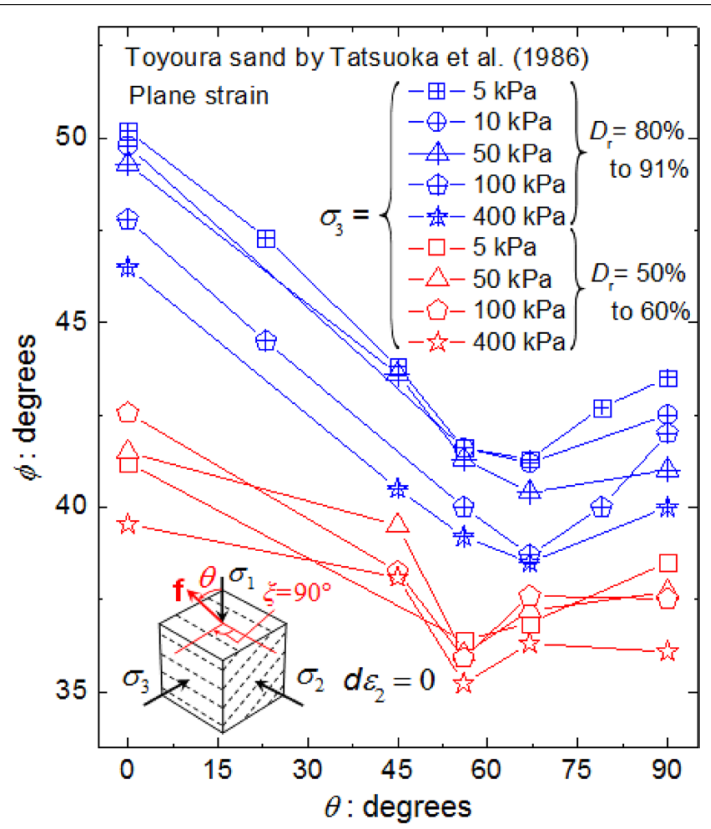

Fig. 4 Anisotropic strength of Toyoura sand in plane strain compression tests 
Toyoura sand with isotropic fabric, and Tochigi sand with anisotropic fabric as shown in Fig. 5.

Toyoura sand was more elongated than Tochigi sand. Therefore, Toyoura sand displayed a steeper checkmark shape than the Tochigi sand, which confirmed the elongated sands can develop stronger anisotropic strength responses. The same observations reported by Lade et al. [14].

To create an isotropic specimen, Oda [5] used a hand plunger to plunge into the Toyoura sand specimen to destroy the initial cross anisotropic arrangement of particles generated by air-pluviation method, resulting in an isotropic Toyoura sand specimen. The test results of isotropic specimen for $\vartheta=0^{\circ}$ to $90^{\circ}$ are shown in Fig. 5. Expectedly, a nearly flat line was found, which confirmed strength responses of isotropic specimen were independent of $\vartheta$.

Lam and Tatsuoka [15] considered three structures (Figs. 1b to d) as shown in Fig. 6. Three common strain conditions were considered: symmetric triaxial test $(b=0)$, triaxial extension test $(b=1.0)$ and plane strain compression test $(0.2<b<0.3)$. The confining stress $\sigma_{3}$ was $100 \mathrm{kPa}$ and relative density $D_{\mathrm{r}}$ was $74 \%$ in all the tests. For symmetric triaxial test $(b=0)$ at structures 2 and 3 , the $\phi$ decreased as increasing $\xi$, which agreed with the observation in Fig. 2. It should be noted that at Lam and Tatsuoka [15] did not perform the symmetric triaxial tests at structure 1 but assumed a constant $\phi$ value which was equal to the $\phi$ value at $\vartheta=90^{\circ}$ and $\xi=90^{\circ}$. For plane strain condition, checkmark shape was found at structure 2, which agreed with the observations in Figs. 4 and 5. At structures 1 and 3 , the $\phi$ monotonically decreased as increasing $\vartheta$. For triaxial extension test $(b=1)$, the $\phi$ values displayed checkmark shapes at structures 2 . The strength responses at structure 1 were the same as structure 2 because of the same boundary conditions. Lam and Tatsuoka [15] did not perform the symmetric triaxial extension tests at

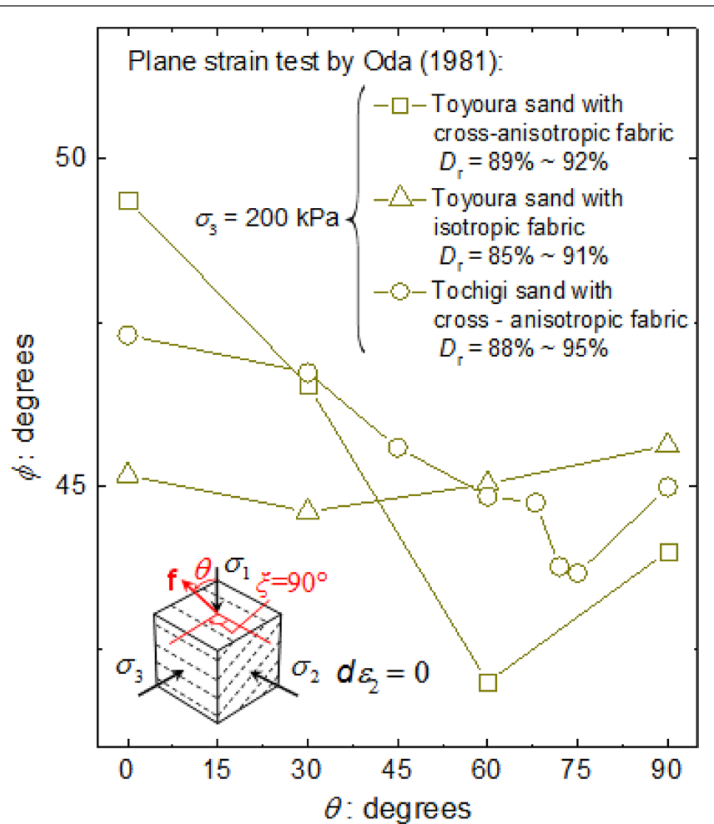

Fig. 5 Anisotropic strength of cross-anisotropic Toyoura sand, isotropic Toyoura sand, and cross-anisotropic Tochigi sand in plane strain compression tests 


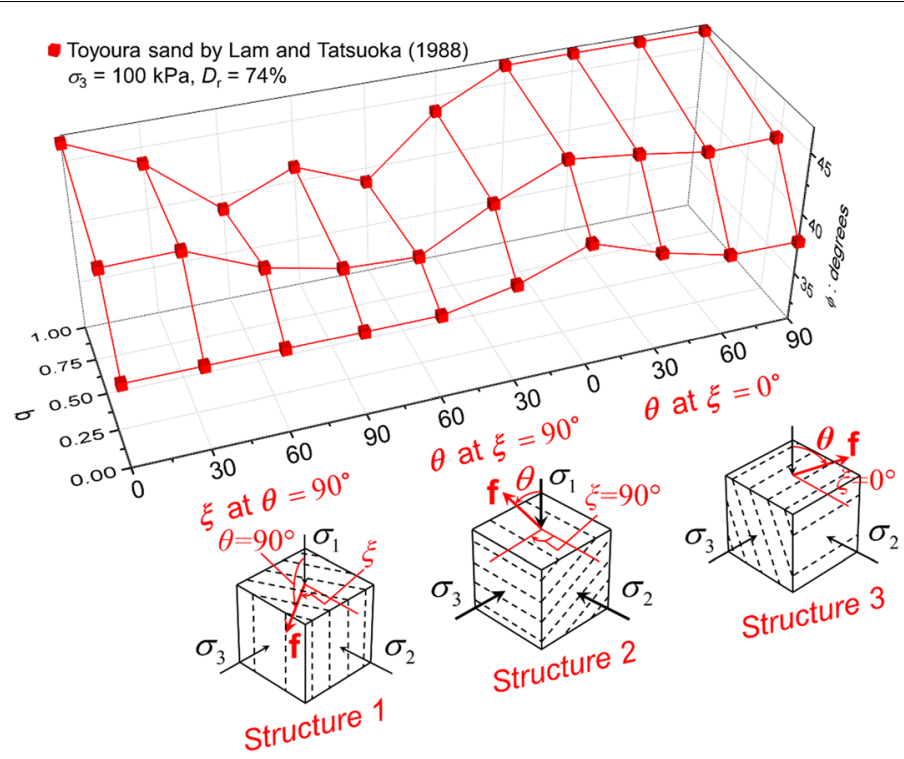

Fig. 6 Anisotropic strength of Toyour sand in plane strain compression tests in three fabric configurations

structure 3, but assumed a constant $\phi$ value which was the same as the $\phi$ value at $\vartheta=0^{\circ}$ and $\xi=90^{\circ}$. The anisotropic strength response was more pronounced at larger $b$ values in structure 2. This agreed with the observation made from Nevada sand in Fig. 3a and Leighton Buzzard sand in Fig. 3b.

\section{Development anisotropic failure criterion based on experimental observations Formulation of anisotropic failure criterion}

The checkmark relationships between $\vartheta$ or $\xi$ and soil strength are comparable to strength variation of jointed rock mass as reported by Zhang [35]. The joints create planes of weakness in rocks. Therefore, rocks reached the lowest strength when failure plane overlaps with the joints. The strength increases as the orientation of failure plane and the orientation of joints depart from each other. We hypothesize that the same concept can be used in this study to develop the anisotropic failure criterion of sands. The deposit plane of sands creates a plane of weakness. Therefore, the strength of cross-anisotropic sands depends on the relative orientations between potential failure plane and deposit plane. Sands reach the minimum strength when the potential failure plane and deposit plane are overlapping with each other, and the strength increases when they diverge from each other.

A "Spatial Mobilized Plane" (SMP) developed by Nakai and Matsuoka [30, 31] is used in this study to define the potential failure plane. A typical soil specimen is shown in the three-dimensional stress space in Fig. 7a, where axes I, II, and III are the opposite directions of major, intermediate, and minor principal stresses $\left(\sigma_{1}, \sigma_{2}\right.$, and $\sigma_{3}$ ) respectively. Figure $7 \mathrm{~b}$ shows the Mohr circles $O_{1}, O_{2}$, and $O_{3}$ at failure state. The failure envelope using the circle $O_{1}$ formed by $\sigma_{1}$ and $\sigma_{3}$ determines the mobilized friction angle $\phi_{m o b}^{13}$ as shown in Fig. 7b. The failure envelope using the circle $O_{2}$ formed by $\sigma_{1}$ and $\sigma_{2}$ determines the mobilized friction angle $\phi_{m o b}^{12}$ as shown in Fig. 7b. 


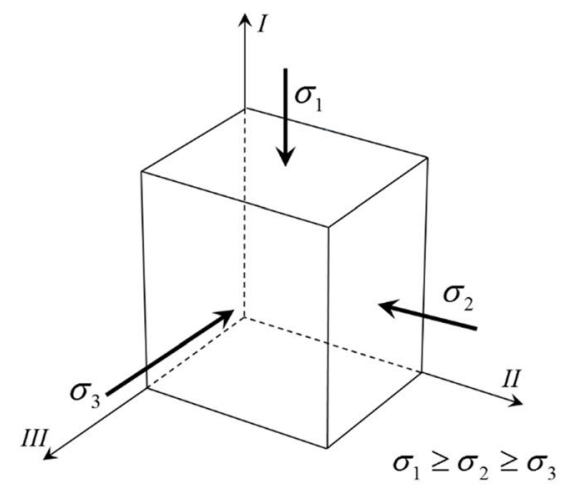

(a)

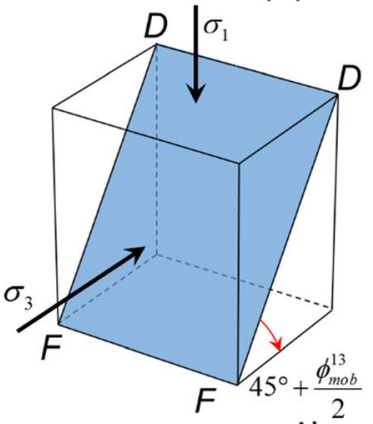

(c) $\underset{45^{\circ}+\frac{\phi}{2}}{11}$

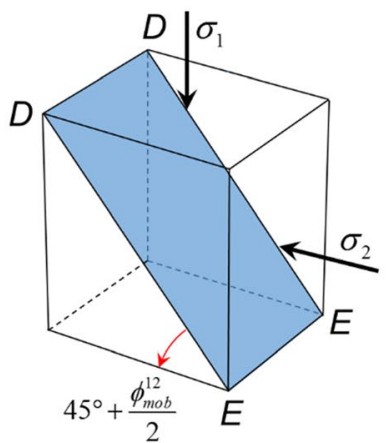

(d)

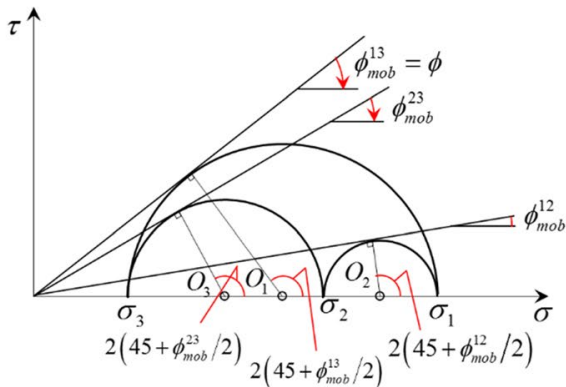

(b)

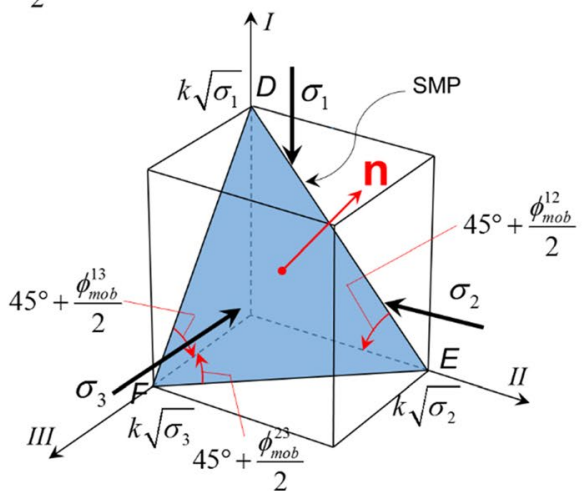

(f)

Fig. 7 The spatial mobilized plane proposed by Nakai and Tatsuoka $[30,31]$

The failure envelope using the circle $O_{3}$ formed by $\sigma_{2}$ and $\sigma_{3}$ determines the mobilized friction angle $\phi_{m o b}^{23}$ as shown in Fig. 7b.

Based on Nakai and Matsuoka [30,31], knowing the mobilized friction angle $\phi$, the inclination angle of failure plane can be determined as $45^{\circ}+\phi / 2$, also called "Mobilized Plane" or the "Plane of maximum oblique". Therefore, three mobilized friction angles $\phi_{m o b}^{13}, \phi_{m o b}^{12}$, and $\phi_{m o b}^{23}$ determine three mobilized planes in Fig. $7 \mathrm{c}-\mathrm{e}$ respectively. The inclination angles of three mobilized planes are determined as $45^{\circ}+\phi_{\text {mob }}^{13}$ $/ 2,45^{\circ}+\phi_{m o b}^{12} / 2$, and $45^{\circ}+\phi_{m o b}^{23} / 2$. 
Nakai and Matsuoka $[30,31]$ integrated three mobilized planes in Fig. 7c-e to generate a SMP as shown in Fig. 7f. The Mohr-coulomb failure plane does not consider effects of intermediate principal stress while the SMP considered effects of three principal stresses.

Intersects of SMP with axes I, II, and III are proportional to the square roots of the principal stresses. Nakai and Matsuoka [30,31] showed that normal vector of SMP $\mathbf{n}=\left(n_{1}, n_{2}\right.$, and $n_{3}$ ) can be computed as:

$$
\mathbf{n}=\left[\begin{array}{lll}
\frac{I_{3}}{\sigma_{1} I_{2}} & \sqrt{\frac{I_{3}}{\sigma_{2} I_{2}}} & \sqrt{\frac{I_{3}}{\sigma_{3} I_{2}}}
\end{array}\right]
$$

where $I_{2}=$ the second stress invariant, $\sigma_{1} \sigma_{2}+\sigma_{2} \sigma_{3}+\sigma_{1} \sigma_{3}$; and $I_{3}=$ the third stress invariant, $\sigma_{1} \sigma_{2} \sigma_{3}$.

The fabric direction is defined as:

$$
\mathbf{f}=[\cos (\theta) \sin (\theta) \cos (\xi) \sin (\theta) \sin (\xi)]
$$

Therefore, the relative orientation between deposit plane and SMP can be quantified by the spatial angle between $\mathbf{f}$ and $\mathbf{n}$ :

$$
\begin{aligned}
\delta & =\operatorname{acos}(\mathbf{f} \cdot \mathbf{n}) \\
& =\operatorname{acos}\left(\cos (\theta) \sqrt{\frac{I_{3}}{\sigma_{1} I_{2}}}+\sin (\theta) \cos (\xi) \sqrt{\frac{I_{3}}{\sigma_{2} I_{2}}}+\sin (\theta) \sin (\xi) \sqrt{\frac{I_{3}}{\sigma_{3} I_{2}}}\right)
\end{aligned}
$$

Based on our hypothesis, small $\delta$ values mean the orientations of deposit plane and failure plane are close and small strength ( $\phi$ values) is expected, while large $\delta$ values mean deposit plane diverges from failure plane and large strength ( $\phi$ values) is expected. We testified this hypothesis using Lade et al's [14] test results in Fig. 3a and Lam and Tatsuoka's [15] test results in Fig. 6.

Using Eqs. (1) to (3), the $\delta$ values as a function of $b$ and $\vartheta$ values of Lade et al.s [27] tests are computed as shown in Fig. 8. The $\delta$ values display checkmark shapes as $\vartheta$ increasing from 0 to $90^{\circ}$. The $\delta$ values reach local minima at $\vartheta=67.5^{\circ}$. This agrees with observation in Fig. 3 that Nevada sand reaches the minimum strength at $\vartheta=67.5^{\circ}$. In addition, the checkmark shapes tend to become steeper when $b$ increases from 0 to 1 . This well agrees with the observation in Fig. 3 that stronger anisotropic responses are observed at larger $b$ values.

Using Eqs. (1) to (3), the $\delta$ values as a function of $b, \vartheta$ and $\xi$ of Lam and Tatsuoka's [15] tests are computed in Fig. 9. The shape of $\delta$ surface agrees with the shape of $\phi$ surface in Fig. 6 . Figures 8 and 9 proves the hypothesis that anisotropic strength can be characterized by the concept of relative orientations between deposit plane and failure plane of sands.

The next step is to develop an anisotropic failure criterion based on the parameter $\delta$. We proposed the following function is to correlate $\delta$ with strength of soils:

$$
f=\eta_{0}(1+\Psi \delta)
$$

where $f$ is a function of stresses to describe a failure criterion for quantifying strength of sands; $\delta$ quantifies the relative orientations between deposit plane and SMP which is computed from Eq. (3); $\Psi$ is a scalar describing slope of the checkmark. The term $(1+\Psi \delta)$ essentially maps the shapes of $\delta$ curves to the shapes of strength curves while the parameter $\eta_{0}$ upscale the $(1+\Psi \delta)$ curves to match the measured strength curves. 


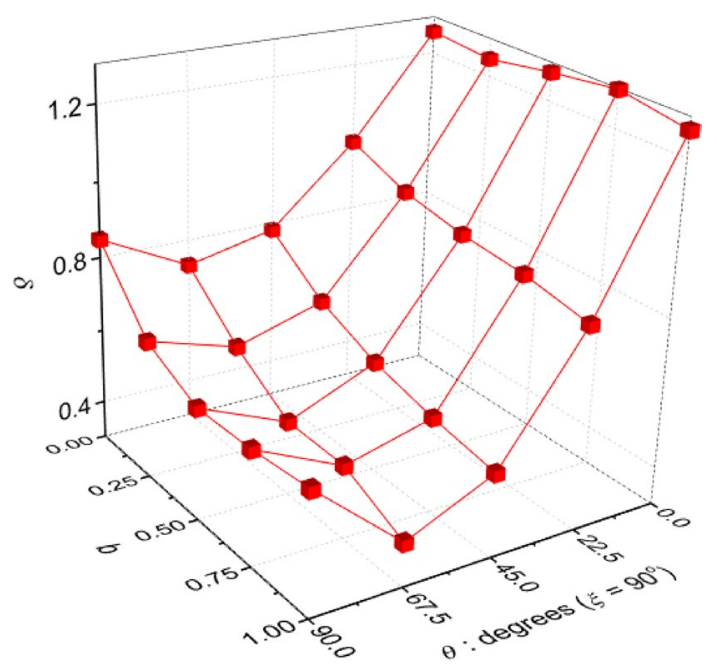

Fig. 8 The spatial angle $\delta$ of Nevada sand as a function of $b$ and $\vartheta$ values from Lade et al's [27] tests

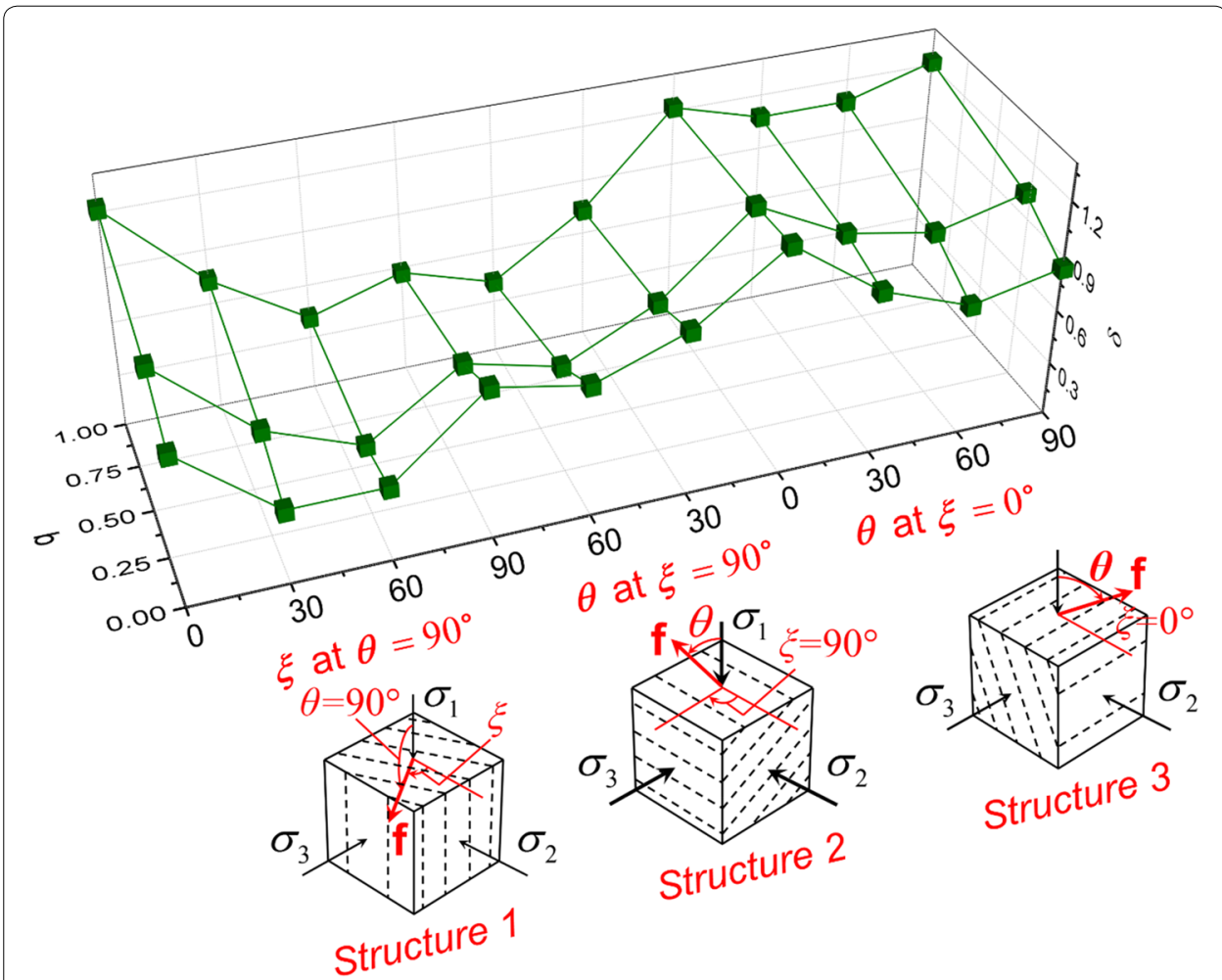

Fig. 9 The spatial angle $\delta$ of Toyoura sand as a function of $b$ and $\vartheta$ values from Lam and Tatsuoka's [15] tests

The well-known failure criterion proposed by Lade [17] is used as $f$ in Eq. (4). Therefore, the anisotropic Lade's failure criterion is formulated as: 


$$
\left(\frac{I_{1}^{3}}{I_{3}}-27\right)\left(\frac{I_{1}}{p_{a}}\right)^{m}=\eta_{0}(1+\Psi \delta)
$$

where $I_{1}=$ the first stress invariant, $\sigma_{1}+\sigma_{2}+\sigma_{3} ; p_{\mathrm{a}}=$ atmospheric pressure in the same units of stresses. The value of $I_{1}^{3} / I_{3}$ equals 27 at the hydrostatic axis. The parameter $m$ is employed to describe curvature of the failure surface in the meridian planes.

\section{Parameter calibration}

There are three parameters in Eq. (5): $m, \eta_{0}$ and $\Psi$. Evidently, if the mean effective stress $p^{\prime}$ is constant in the tests, $m$ will not affect results and can be set as zero. Therefore, Eq. (5) can be rewritten as:

$$
\left(\frac{I_{1}^{3}}{I_{3}}-27\right)=\eta_{0}+\eta_{0} \Psi \delta
$$

Determination of two parameters $\eta_{0}$ and $\Psi$ requires at least two experiments at two fabric directions. If more data points at different fabric orientations are available, all of the test data can be plotted in the space of $\left(I_{1}^{3} / I_{3}-27\right)$ versus $\delta$ to determine a best fitting line. The intercept of the best fitting line determines $\eta_{0}$. Then, the slope of the best fitting line determines $\eta_{0} \Psi$.

For example, the 25 torsion shear tests data from Lade et al. [14] are replotted in $\left(I_{1}^{3} / I_{3}\right.$ $-27)-\delta$ space in Fig. 10. The two abnormal points under test conditions of $(\vartheta, \mathrm{b})=(0$, $0.75)$ and $(0,1.0)$ are not considered in the fitting. The remaining 23 points are used to fit a line as shown in Fig. 10. The intercept and slope of the best fitting line are 4.92 and 27.16 respectively. Therefore, we have $\eta_{0}=4.92$ and $\eta_{0} \Psi=27.16$. Then, $\eta_{0}$ is determined as 4.92 and $\Psi$ is determined as $27.16 / 4.92=5.52$ as shown in Fig. 10.

If the mean effective stresses are not constant (usually different confining stresses are used), all the three parameters $m, \eta_{0}$ and $\Psi$ are required to be determined, which includes

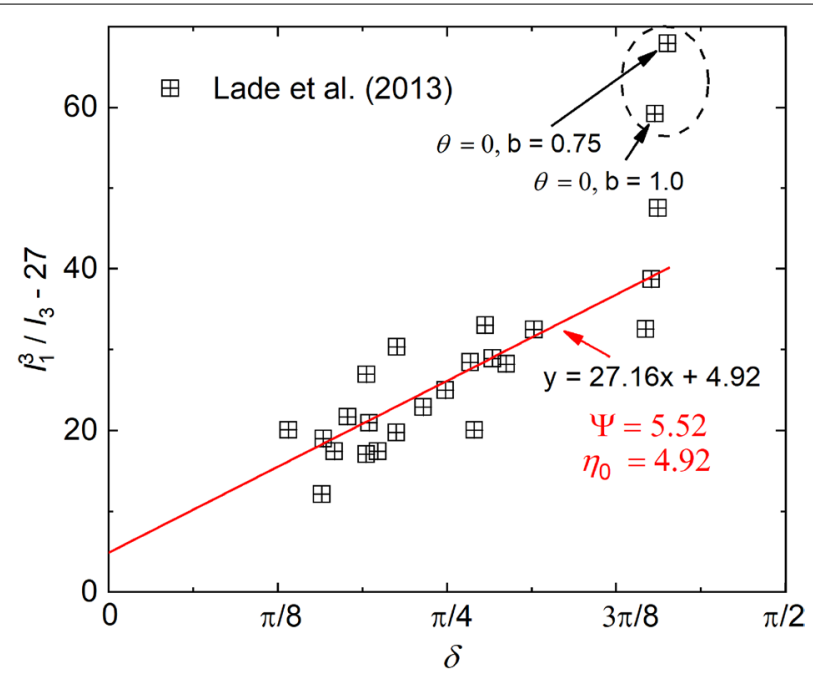

Fig. 10 Model calibration for constant mean effective stress condition 
two steps. Firstly, the $\Psi$ can be determined by plotting $\left(I_{1}^{3} / I_{3}-27\right)$ versus $\delta$ and fitting a line for each confining stress level. The results of Toyoura sand at dense condition in Fig. 4 are used for an example as shown in Fig. 11a. Five $\Psi$ values are obtained. These $\Psi$ values are very close to each other, so they are used to compute an average $\Psi$ value, $\Psi=4.35$.

In the second step, the $m$ and $\eta_{0}$ can be determined by plotting $\ln \left[\left(I_{1}^{3} / I_{3}-27\right) /\right.$ $(1+\Psi \delta)]$ against $\ln \left(p_{\mathrm{a}} / I_{1}\right)$ for all the test data and finding a best fitting straight line. The intercept and slope are $\exp \left(\eta_{0}\right)$ and $m$ respectively. All the test results are replotted in Fig. 11b. Therefore, the $m$ and $\eta_{0}$ are computed as 0.058 and 6.54 respectively.

\section{Evaluation of the proposed failure criterion}

\section{Torsion shear tests}

The $\phi$ values of Nevada sand by Lade et al. [27] in Fig. 3a are replotted in three dimensional space in Fig. 12. Equation (5) is used to predict the $\phi$ values. The model parameters
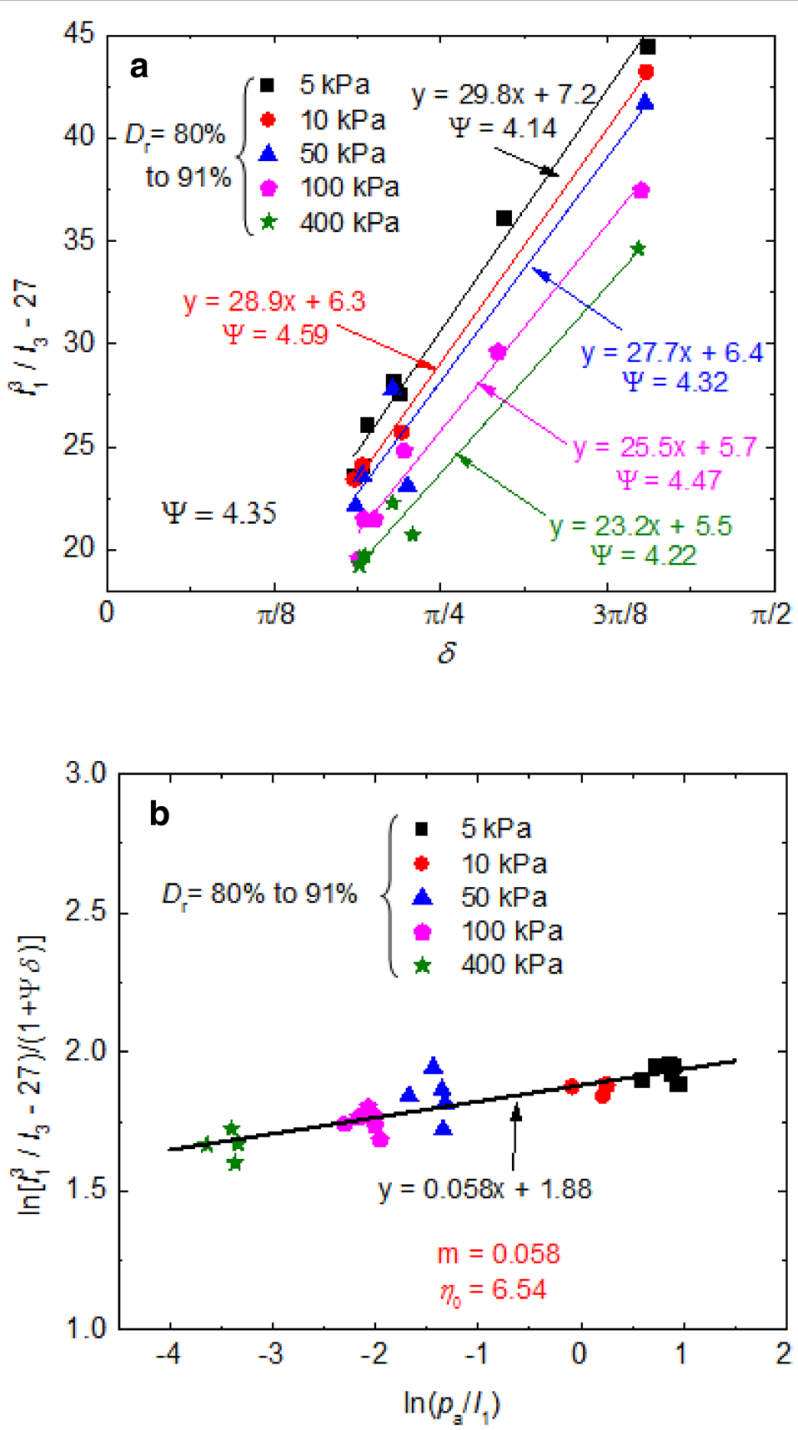

Fig. 11 Model calibration for general condition 
are determined as $m=0, \eta_{0}=4.92$ and $\Psi=5.52$ as shown in Fig. 10. The predictions are shown in Fig. 12. The predictions exhibit the checkmark shapes and capture the minimum strength at $\vartheta=67.5^{\circ}$. The predictions generally agree with measurements except three points at the locations of $(\vartheta, \mathrm{b})=\left(67.5^{\circ}, 0.75\right),\left(0^{\circ}, 0.75\right),\left(0^{\circ}, 1.00\right)$. Rodriguez and Lade [32] pointed out that the values at $\left(0^{\circ}, 0.75\right)$ and $\left(0^{\circ}, 1.00\right)$ are inaccurate due to testing errors. No explanations were given by Rodriguez and Lade [32] for the low strength at point $\left(67.5^{\circ}, 0.75\right)$. The mean absolute difference between predictions and measurements (MAD) is computed as $2.3^{\circ}$ considering all the points which reduces to $1.5^{\circ}$ if three abnormal points are excluded.

Rodriguez and Lade [32] proposed an anisotropic failure criterion by combining Lade's isotropic failure criteria [17] and the fabric tensor proposed by Pietruszczak and Mroz [24, 25] which yield a five-parameter failure criterion. They evaluated their criterion using the same dataset from Lade et al. [14]. The formulation and parameter settings of Rodriguez and Lade [32] are not expanded herein. Their predictions are also presented in Fig. 12 as a comparison. As shown, the three aforementioned points also depart from Rodriguez and Lade's [32] predictions. The computed MAD is $2.9^{\circ}$ with three abnormal points whereas reduces to $2.0^{\circ}$ without three abnormal points. Rodriguez and Lade's [32] failure criterion yields slight higher MADs than this study because their failure criterion over-predicts five points at $(\vartheta, \mathrm{b})=\left(45^{\circ}, 0\right),\left(45^{\circ}, 0.25\right)$, $\left(67.5^{\circ}, 0\right),\left(67.5^{\circ}, 0.25\right)$, and $\left(67.5^{\circ}, 0.5\right)$, where predictions of this study are closer to measurements.

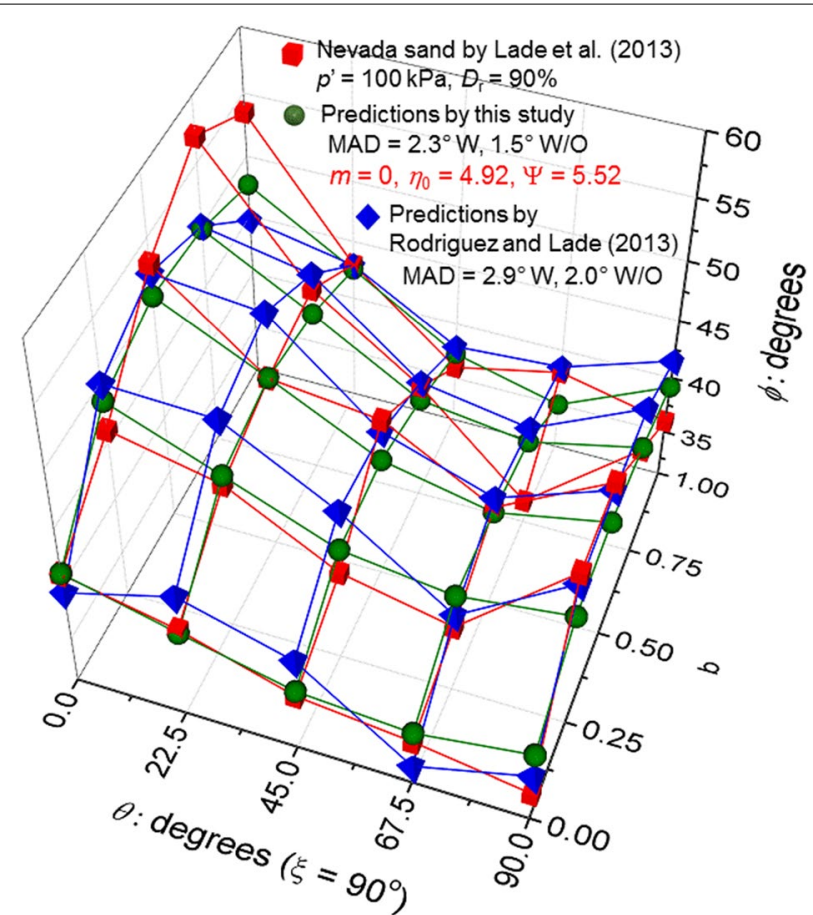

Fig. 12 Comparison between torsion shear test results of Nevada sand and predictions by this study and by Rodriguez and Lade [32] 
For $b=0$ tests, although both this study and Rodriguez and Lade's [32] failure criterion predict a checkmark shape which disagrees the laboratory observation. However, this study still gives relatively better predictions than Rodriguez and Lade [32].

The $\phi$ values of Leighton Buzzard sand by Yang et al. [16] in Fig. 3b are replotted in three-dimensional space as cubes in Fig. 13. Equation (5) is used to predict the $\phi$ values. The $m$ is set as 0 and other two parameters $\eta_{0}$ and $\Psi$ are determined by plotting $\left(I_{1}^{3} / I_{3}\right.$ - 27) versus $\delta$ and fitting a line. The computed $\eta_{0}$ and $\Psi$ values are 7.33 and 2.40 respectively. The predictions successfully capture the checkmark shape presented by measurements. However, the predicted minimum $\phi$ values are at $\vartheta=60^{\circ}$, but the measured minimum $\phi$ values are at $\vartheta=70^{\circ}$. Predictions well match the measurements with a MAD of $1.65^{\circ}$ (Fig. 13).

\section{Symmetrical triaxial tests}

Equation (5) is used to predict the anisotropic strength of sands in symmetrical triaxial tests in Fig. 2. For Cambria sand, Leighton Buzzard sand, and Ham rive sand, the parameter $m$ is set as zero and the rest two parameters $\eta_{0}$ and $\Psi$ are determined by plotting $\left(I_{1}^{3} / I_{3}-27\right)$ versus $\delta$ and fitting a line. The predictions and measures are shown in Fig. 14. For Toyoura sand, three parameters $m, \eta_{0}$ and $\Psi$ are determined by two steps as illustrated in Fig. 9. In the first step, $\Psi$ is computed as 0.48 . Then the $\Psi$ value is used in the second step to determine $m$ and $\eta_{0}$ which are 0.106 and 41.79 respectively. As shown in Fig. 14, Eq. (5) predicts $\phi$ values at $\vartheta=0^{\circ}-60^{\circ}$ while overpredicts $\phi$ values beyond $60^{\circ}$. However, such overpredictions are very minor, less than $2^{\circ}$.

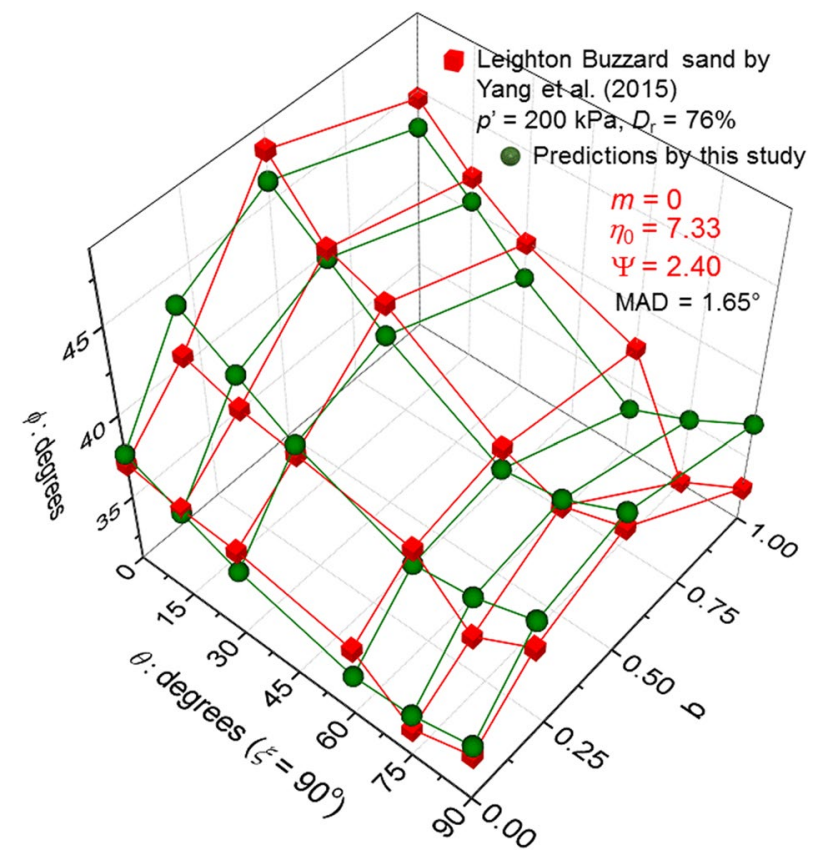

Fig. 13 Comparison between torsion shear test results of Leighton Buzzard sand by Yang et al. [16] and predictions by this study 


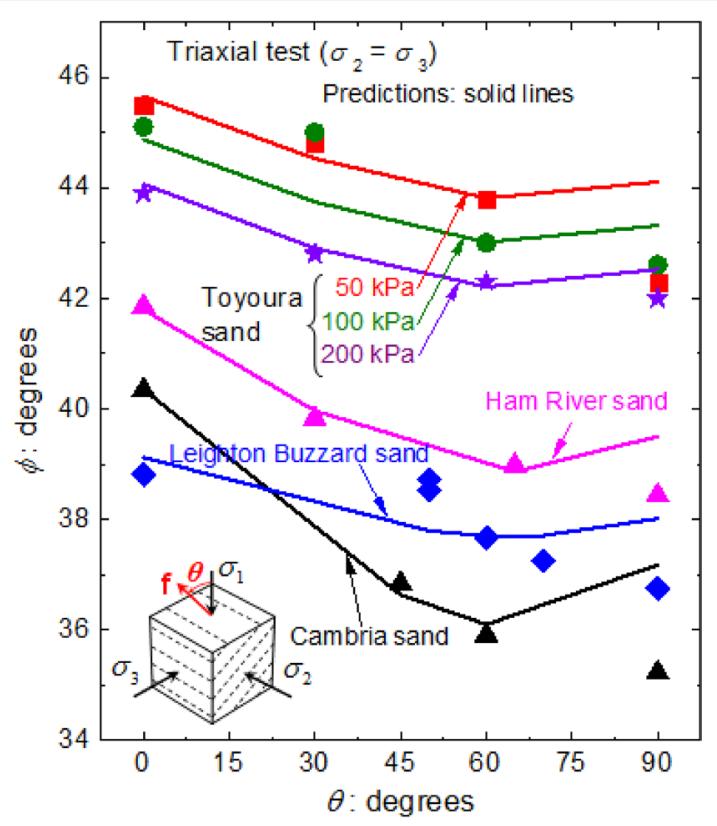

\begin{tabular}{|c|c|c|c|c|c|}
\hline & Measurements & $\Psi$ & $\eta_{0}$ & $m$ & MAD \\
\hline & Cam & 2.28 & 9.48 & 0 & $0.59^{\circ}$ \\
\hline & uzzard sand & 0.32 & 23.50 & 0 & $0.62^{\circ}$ \\
\hline A & Ham River sand & 0.93 & 19.09 & 0 & $0.35^{\circ}$ \\
\hline 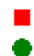 & $\begin{array}{l}\text { Toyoura }(50 \mathrm{kPa}) \\
\text { Toyoura }(100 \mathrm{kPa})\end{array}$ & 0.48 & 4179 & 0.106 & $0.44^{\circ}$ \\
\hline & Toyoura (200 kPa) & & & & \\
\hline
\end{tabular}

Fig. 14 Comparison between triaxial test results of four sands and predictions by this study

\section{Plane strain compression tests}

For plane strain compression tests, usually $\sigma_{1}$ and $\sigma_{3}$ values are reported by literature but $\sigma_{2}$ values are not. However, all of the three principal stresses are required when using Eq. (4). Therefore, a statistical $b$ value will be determined based on existing testing results. This $b$ value will be used to estimate $\sigma_{2}$ values whenever they are not reported by original studies.

Figure 15 collects the computed $b$ values at peak strength using the testing data of Oda et al. [7] and Tatsuoka et al. [13] in which all the principal stresses are measured. As shown, the $b$ values span in a range of 0.2 to 0.3 with an average of 0.24 . The same value is observed by Lam and Tatsuoka [15] in their plane strain compression tests. Therefore, $b=0.24$ is used in this study.

Equation (5) is used to predict $\phi$ values of Toyoura sand tested by Tatsuoka et al. [13] using plane strain tests. For dense condition, the model parameters are calibrated as $m=0.058, \eta_{0}=6.54$ and $\Psi=4.35$. The predictions and measurements are compared in Fig. 16a. The predictions agree with measurements at different confining stresses very well. The MAD of all the data is only $0.44^{\circ}$. For medium dense condition, the model parameters are calibrated as $m=0.03, \eta_{0}=8.84$, and $\Psi=1.52$. Predictions and measurements are shown in Fig. 16b. Predictions well match measurements with a MAD of $0.72^{\circ}$.

Toyoura sand was also used by Oda et al. [7] in plane strain compression tests. All the tests were performed at dense condition $\left(D_{\mathrm{r}}=89-92 \%\right)$ and under four confining stresses $\sigma_{3}=50 \mathrm{kPa}, 100 \mathrm{kPa}, 200 \mathrm{kPa}$, and $400 \mathrm{kPa}$. The results are shown in 


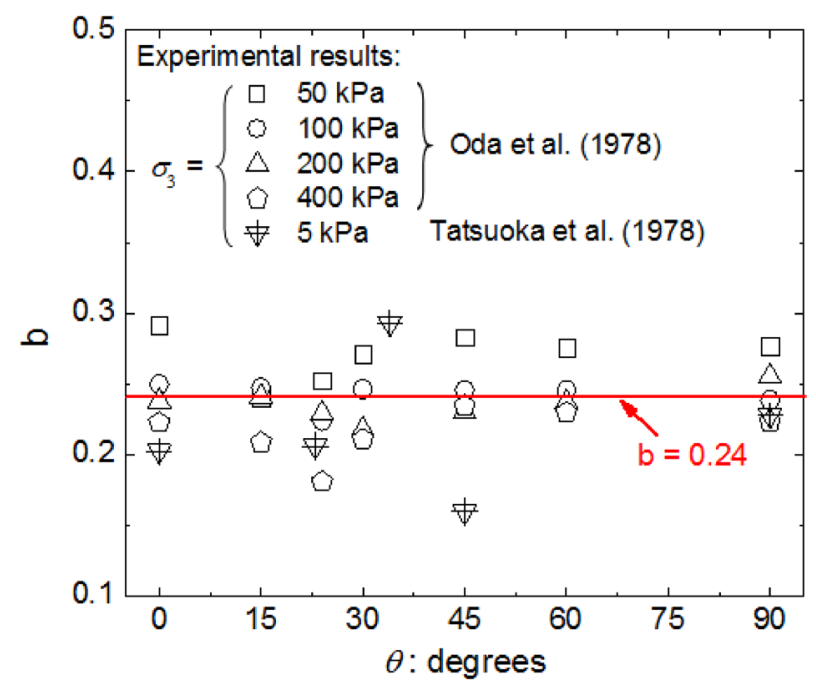

Fig. 15 The $b$ at failure in plane strain compression tests

Fig. 17. Equation (5) is used to predict $\phi$ values. The model parameters are calibrated as $m=0.24, \eta_{0}=14.38$, and $\Psi=4.35$. The predictions agree with measurements. The MAD is $0.85^{\circ}$ for all the data.

Equation (5) is used to predict the plane strain compression test results of Oda [7] as shown in Fig. 18. Oda [7] did not provide the intermediate stress $\sigma_{2}$ measurements. Therefore, the $b=0.24$ is used herein to compute $\sigma_{2}$. The Tochigi sand is more spherical than Toyoura sand. Therefore, the $\Psi$ values for Tochigi sand is smaller than Toyoura sand. For isotropic Toyoura sand, the $\Psi$ is set as zero which yields a flat line. The predictions generally agree with measurements with MADs of $0.43,0.51$, and 0.28 for anisotropic Toyoura sand, Tochigi sand, and isotropic Toyoura sand respectively.

Park and Tatsuoka [36] performed a series of plane strain compression tests on five different sands: Monterey sand, Hostun sand, Silica sand, Ticino sand, and Karlsruhe sand. All the tests are performed under the confining stress of $88 \mathrm{kPa}$ and density condition $\left(D_{\mathrm{r}}=80-90 \%\right)$. The results are shown in Fig. 19. The strength responses of the Hostun sand, Karlsruhe sand, and Hostun sand display the checkmark shapes. However, Monterey sand and Tichino sand do not follows checkmark shape at $\vartheta=90^{\circ}$. Park and Tatsuoka [36] did not provide the intermediate stress $\sigma_{2}$ measurements. The $b=0.24$ is used herein to compute $\sigma_{2}$.

The parameter $m$ is set as zero in all prediction. The other two parameter $\eta_{0}$ and $\Psi$ are different for each sand and their values are shown in Fig. 19. Excellent agreements between predictions and measurements are observed, expect for the $\phi$ values of Monterey sand and Tichino sand at $\vartheta=90^{\circ}$ and the $\phi$ value of Silica sand at $\vartheta=60^{\circ}$.

Equation (5) is used to predict the $\phi$ values of plane strain compression test results of Toyoura sand from Lam and Tatsuoka [15] as shown in Fig. 20. They reported their b values were in a range of 0.2 to 0.3 . Therefore, the $b=0.24$ is used herein to compute $\sigma_{2}$. The parameter $m$ is set as zero and other two parameters are set as $\eta_{0}=12.89$ and $\Psi=1.48$. Good agreements are found between predictions and measurements. The overall MAD is computed as $1.3^{\circ}$. 

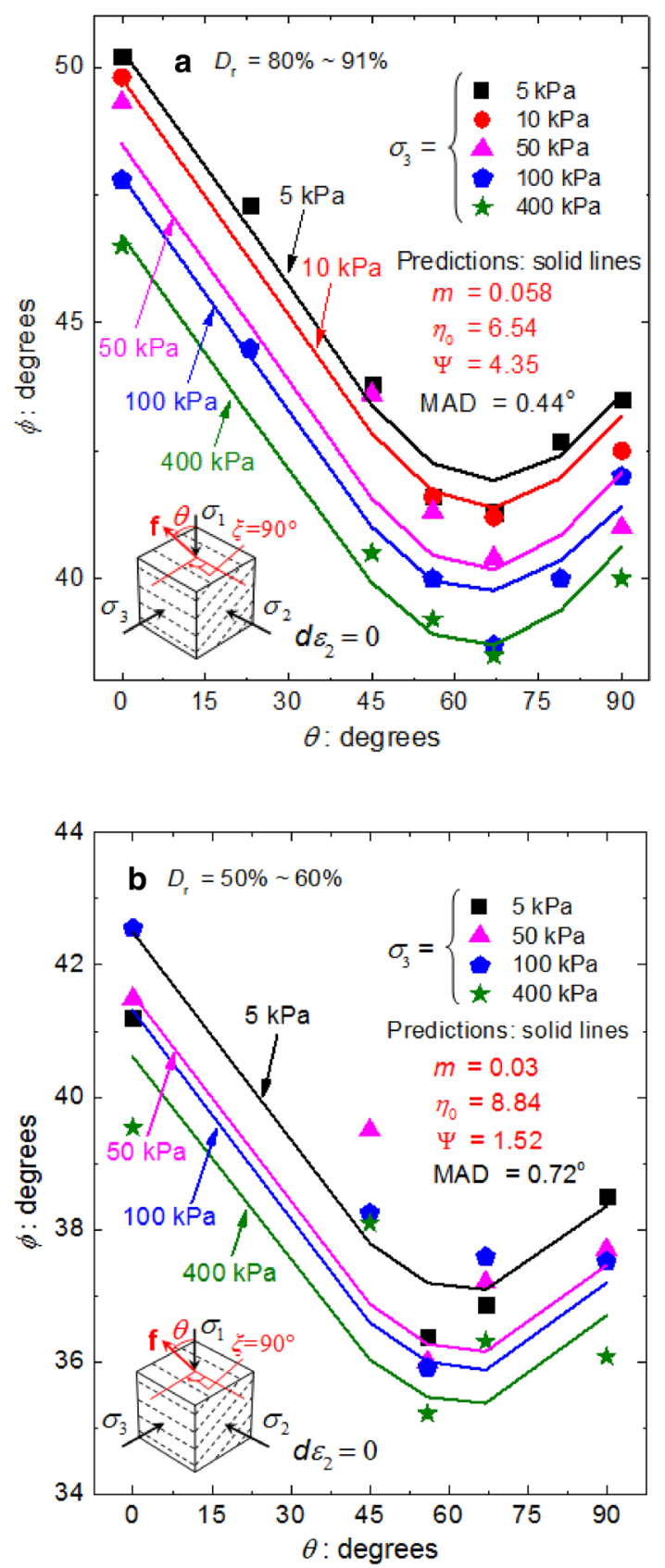

Fig. 16 Comparison between plane strain compression test results of Toyoura sand by Tatsuoka et al. [13] and predictions by this study

\section{Discussion}

1. The anisotropic strength of sands depends on both fabric direction and intermediate stress. For $b>0$ tests, $\phi$ values displayed checkmark shape as increasing $\vartheta$ values, while for $\mathrm{b}=0$ tests, $\phi$ values monotonically decreases as increasing $\vartheta$ values. The proposed failure criterion successfully captures the checkmark relationship between 


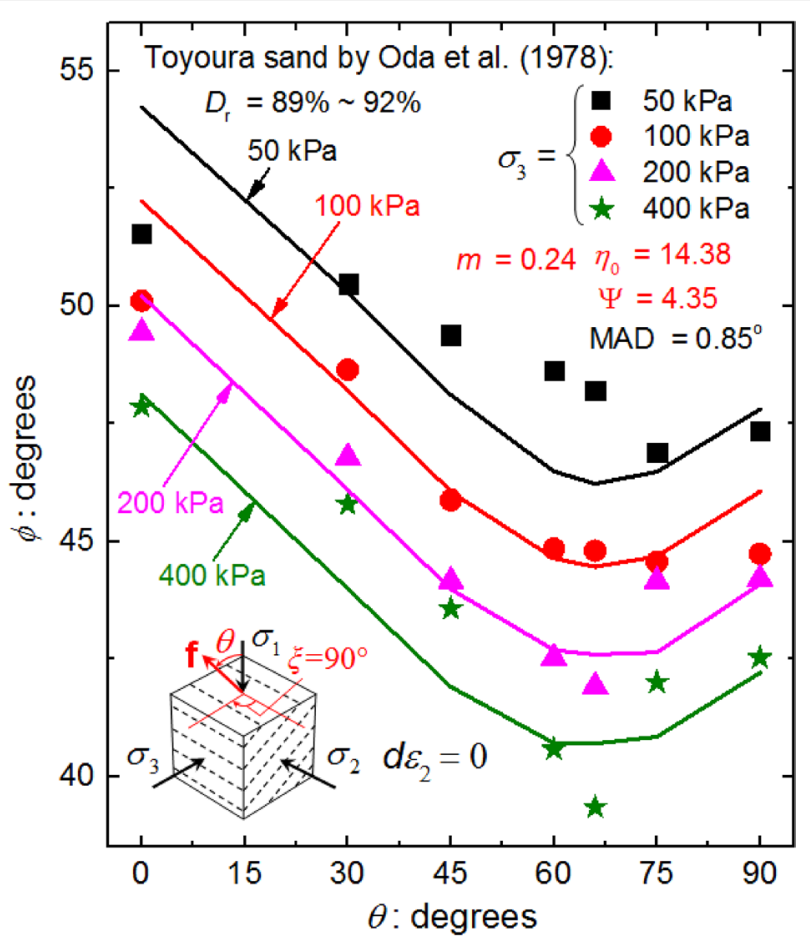

Fig. 17 Comparison between plane strain compression test results of Toyoura sand by Oda et al. [7] and predictions by this study

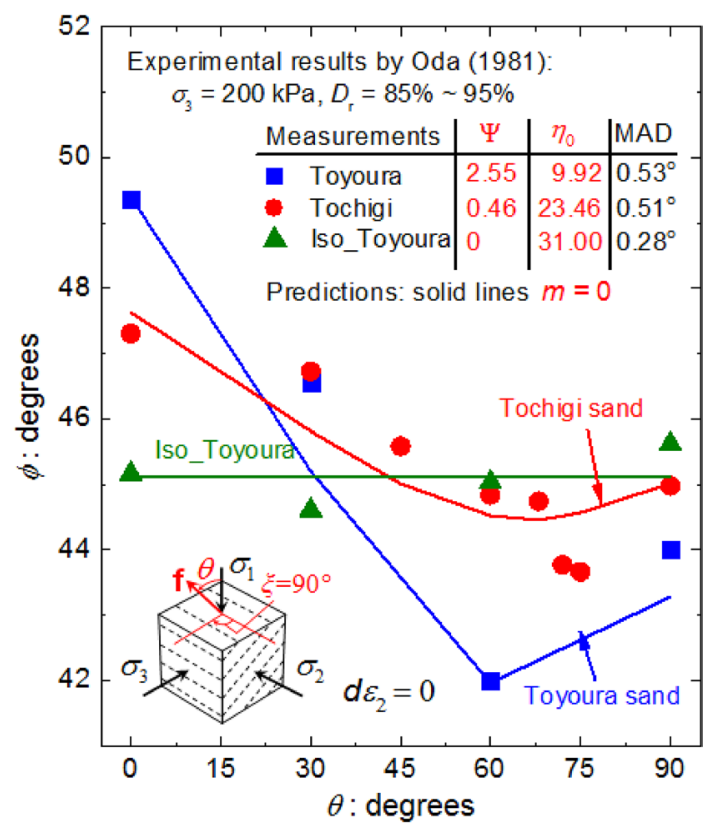

Fig. 18 Comparison between plane strain compression test results of cross-anisotropic Toyoura sand, cross-anisotropic Tochigi, and isotropic Toyoura sand by Oda et al. [7] and predictions by this study 


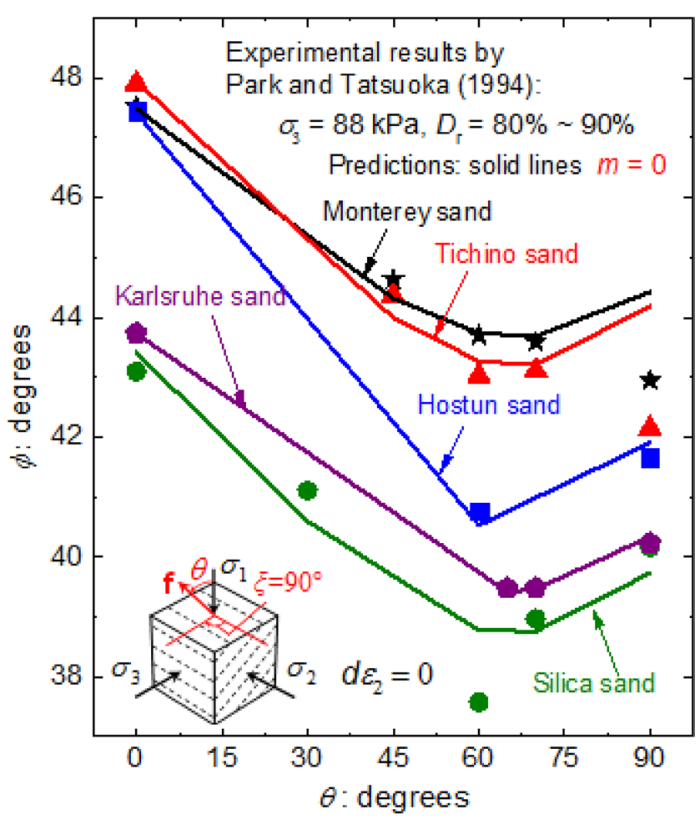

\begin{tabular}{ll|r|r|r}
\multicolumn{1}{c|}{ Measurements } & \multicolumn{1}{c|}{$\Psi$} & \multicolumn{1}{c|}{$\eta_{0}$} & MAD \\
\hline Monterey sand & 0.61 & 20.73 & $0.39^{\circ}$ \\
- Hostun sand & 2.24 & 9.60 & $0.15^{\circ}$ \\
Silica sand & 1.00 & 12.30 & $0.53^{\circ}$ \\
- Ticino sand & 0.88 & 17.95 & $0.56^{\circ}$ \\
- Karlsruhe sand & 0.84 & 13.81 & $0.05^{\circ}$
\end{tabular}

Fig. 19 Comparison between plane strain compression test results of five sands by Park and Tatsuoka [36] and predictions by this study

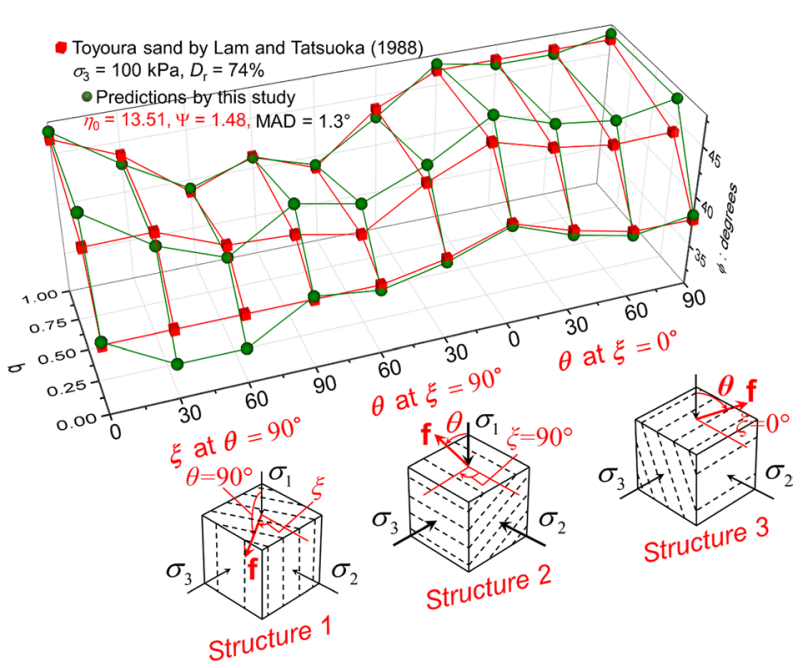

Fig. 20 Comparison between experimental results of Toyoura sand by Lam and Tatsuoka [15] and predictions by this study 
$\phi$ and $\vartheta$, but does not capture the monotonic relationship between $\phi$ and $\vartheta$. As shown in Fig. 14, Eq. (5) overpredicts $\phi$ values when $\vartheta>60^{\circ}$. However, such overpredictions are insignificant, less than $2^{\circ}$.

2. The slope of checkmark reflects the degree of anisotropy in sands, which depends on particle elongation and relative density. Elongated sands at dense condition will develop stronger anisotropy and steeper checkmark shape (Figs. 4 and 5). In Eq. (5), the slope of checkmark is controlled by $\Psi$. Larger $\Psi$ values yield steeper checkmarks (Figs. 14 and 16). Therefore, it is possible to establish a correlation between $\Psi$ values and particle elongations and relative densities. However, there is a lack of systematical data varying particle elongations and relative densities in the literature. This will be the research topic in the future when more data are available.

3. The confining stress (or mean effective stress) will also affect anisotropic strength of sands. Larger confining stress will depress anisotropic responses, and generate flatter checkmark shapes. However, the available data in Fig. 4 shows that similar checkmarks for confining stress in a range of $5 \mathrm{kPa}$ to $400 \mathrm{kPa}$ in plane strain compression tests and therefore the similar $\Psi$ values are determined in Fig. 11a. It implies that small confining stress (e.g. $400 \mathrm{kPa}$ in plane strain compression tests) have negligible effects on anisotropic responses of sands. If larger confining stresses are encountered by readers and different $\Psi$ values are yielded in Fig. 11a, different $\Psi$ values should be determined for different stress levels.

4. Existing experimental data in literature focused on fabric configurations of structure $1\left(\vartheta=90^{\circ}\right.$ and $\left.\xi=0-90^{\circ}\right)$, structure $2\left(\vartheta=0-90^{\circ}, \xi=90^{\circ}\right)$, and structure 3 $\left(\vartheta=0-90^{\circ}, \xi=0^{\circ}\right)$. There is a lack of data for generalized fabric: $\vartheta=0-90^{\circ}$ and $\xi=0-90^{\circ}$. However, this proposed failure criterion have the capability to determine anisotropic strength for generalized fabric. For example, the predicted $\phi$ values for $\mathrm{b}=1$ test under $\vartheta=0-90^{\circ}$ and $\xi=0-90^{\circ}$ conditions are plotted in Fig. 21 . The test results of $b=1$ from Lam and Tatsuoka [15] are superimposed on Fig. 21. The $\phi$ surface exhibits a cone shape with a global minimum at $\vartheta=67^{\circ}$ and $\xi=67^{\circ}$. In future, the accuracy and effectiveness of predictions should be validated when experimental data are available for generalized fabric.

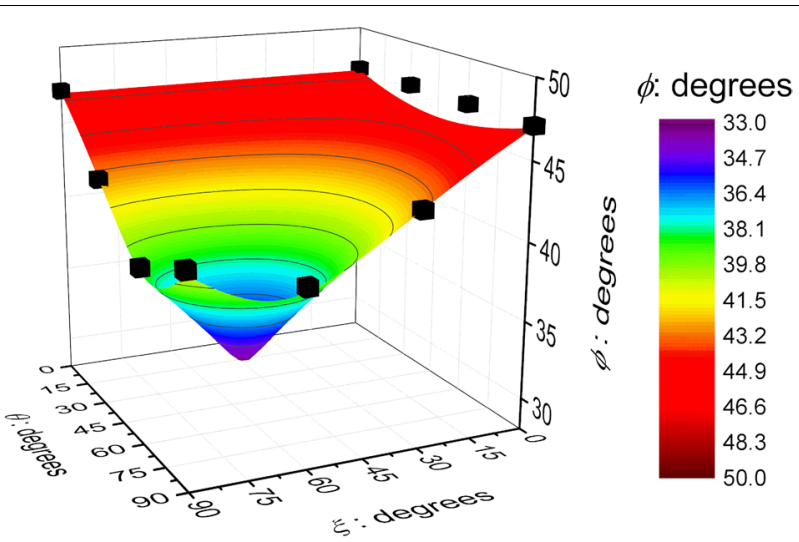

Fig. 21 Predicted anisotropic strength surface $(b=1)$ for generalized fabric 


\title{
Conclusion
}

This paper reviews the experimental studies on anisotropic strength of various sands using symmetric triaxial tests, torsion shear tests, and plane strain compression tests. The results show that anisotropic strength depends on both intermediate stress and fabric direction. When fabric direction is perpendicular to intermediate principal stress $\left(\vartheta=0-90^{\circ}\right.$, $\left.\xi=90^{\circ}\right)$, it is observed that the stronger anisotropic responses occurred at higher $b$ values $\left(\mathrm{b}=\left(\sigma_{2}-\sigma_{3}\right) /\left(\sigma_{1}-\sigma_{3}\right)\right)$. For $\mathrm{b}>0$, the $\phi$ exhibits a checkmark shape and reaches the minimum around $\vartheta=60^{\circ}$ to $70^{\circ}$; and for $\mathrm{b}=0$, the $\phi$ decrease as increasing $\vartheta$.

Based on analysis of experimental results, an anisotropic failure criterion is developed by this study. This criterion is formulated based on the spatial mobilized failure plane developed by Nakai and Matsuoka [30,31] and isotropic failure criterion developed by Lade [17]. The new anisotropic failure criterion only contains three parameters, which can be determined by conventional laboratory tests. This criterion can predict anisotropic strength of sands in common fabric configures: structure $1\left(\vartheta=90^{\circ}\right.$ and $\left.\xi=0-90^{\circ}\right)$, structure 2 $\left(\vartheta=0-90^{\circ}, \xi=90^{\circ}\right)$, and structure $3\left(\vartheta=0-90^{\circ}, \xi=0^{\circ}\right)$. The proposal failure criteria is validated by various sands in symmetrical triaxial tests, torsion shear tests, and plane strain compression tests. The predictions agree well with experimental results, which demonstrate the validity, effectiveness, and robustness of the new anisotropic failure criterion.

\begin{abstract}
List of symbols
$\sigma_{1}$ : The major principal stress; $\sigma_{2}$ : The intermediate principal stress; $\sigma_{3}$ : The miner principal stress; $l_{1}:$ The firstly stress invariant; $l_{2}$ : The second stress invariant; $l_{3}$ : The third stress invariant; $\mathbf{f}$ : Fabric direction or the normal direction of deposit plane; $\mathbf{n}$ : The normal of the spatial mobilized plane; $\vartheta$ : The angle between fabric direction $\mathbf{f}$ and major principal stress $\sigma_{1} ; \xi:$ The angle between fabric direction $\mathbf{f}$ and intermediate principal stress $\sigma_{2} ; \varphi$ : The angle of internal friction; $m, \eta_{0}$ and $\psi$ : The model factors in the proposed anisotropic failure criterion; $\delta$ : The relative orientations between deposit plane and spatial mobilized plane; $\phi_{\text {mob }^{\prime}}^{13} \phi_{\text {mob }}^{12} \phi_{m o b}^{23}$ :The mobilized friction angles in the spatial mobilized plane theory.
\end{abstract}

\section{Acknowledgements}

This material is based upon work supported by the U.S. National Science Foundation under Grant No. CMMI 1917332. Any opinions, findings, and conclusions or recommendations expressed in this material are those of the authors and do not necessarily reflect the views of the National Science Foundation. The authors want to acknowledge the Department of Civil, Construction and Environmental Engineering, lowa State University for providing partial financial support to this research.

\section{Authors' contribution}

QS collected literature data and drafted the manuscript. JZ developed the analytical model. All authors read and approved the final manuscript.

\section{Competing interests}

The authors declare that they have no competing interests.

Received: 13 November 2019 Accepted: 26 May 2020

Published online: 08 June 2020

\section{References}

1. Oda M, Koishikawa I (1979) Effect of strength anisotropy on bearning capacity of shallow footing in a dense sand. Soils Found 19:15-28

2. Azami A, Pietruszczak S, Guo P (2009) Bearing capacity of shallow foundations in transversely isotropic granular media. Int J Numer Anal Meth Geomech 34:771-793. https://doi.org/10.1002/nag.827

3. Oda M (1972) Initial fabric and their relations to mechanical properties of granular materials. Soils Found 12:17-36

4. Oda M (1972) The Mechanism of fabric changes during compressional deformation of sand. Soils Found 12:1-18. https://doi.org/10.1248/cpb.37.3229

5. Oda M (1981) Anisotropic strength of cohensionless sands. J Geotech Eng Div 107:1219-1231. https://doi. org/10.1080/19397030902947041

6. Oda M, Kazama H, Konishi J (1998) Effects of induced anisotropy on the development of shear bands in granular materials. Mech Mater 28:103-111. https://doi.org/10.1016/S0167-6636(97)00018-5

7. Oda M, Koishikawa I, Higuchi T (1978) Experimental study of anisotropic shear strength of sand by plane strain test. Soils Found 18:25-38 
8. Arthur JRF, Menzies BK (1972) Inherent anisotropy in a sand. Géotechnique. https://doi.org/10.1680/ geot.1973.23.1.128

9. Arthur JRF, Phillips AB (1975) Homogeneous and layered sand in triaxial compression. Géotechnique 25:799-815. https://doi.org/10.1680/geot.1975.25.4.799

10. Wong RKS, Arthur JRF (1985) Induced and inherent anisotropy in sand. Geotechnique 35:471-481. https://doi. org/10.1080/19397030902947041

11. Arthur JRF, Chua KS, Dunstan T (1977) Induced anistropy in sand. Geotechnique 27:13-30. https://doi. org/10.1080/19397030902947041

12. Ochiai H, Lade PV (1983) Three-dimensional behavior of sand with anistropic fabric. J Geotech Eng 109:1313-1328. https://doi.org/10.2208/jscej1969.1983.339_147

13. Tatsuoka F, Sakamoto M, Kawamura T, Fukushima S (1986) Strength and deformation characteristics of sand in plane strain compression at extremely low pressures. Soils Found 26:65-84. https://doi.org/10.3208/sandf1972.26.65

14. Lade PV, Rodriguez NM, Van Dyck EJ (2014) Effects of principal stress directions on 3D failure conditions in crossanisotropic sand. J Geotech Geoenviron Eng 140:1-12. https://doi.org/10.1061/(ASCE)GT.1943-5606.0001005

15. Lam W-K, Tatsuoka F (1988) Effects of initial anisotropic fabric and intermediate stress on strength and deformation characteristics of sand. Soils Found 28:89-106

16. Yang LT, Li X, Yu HS, Wanatowski D (2016) A laboratory study of anisotropic geomaterials incorporating recent micromechanical understanding. Acta Geotech 11:1111-1129. https://doi.org/10.1007/s11440-015-0423-7

17. Lade PV (1977) Elasto-plastic stress-strain theory for cohesionless soil with curved yield surfaces. Int J Solids Struct. https://doi.org/10.1016/0020-7683(77)90073-7

18. Lade PV, Abelev AV (2005) Characterization of cross-anisotropic soil deposits from isotropic compression tests. Soils Found 45:89-102

19. Oda M, Nakayama H (1989) Yield function for soil with anisotropic fabric. J Eng Mech 115:89-104. https://doi. org/10.1061/(asce)0733-9399(1989)115:1(89)

20. Li X-S, Dafalias Y (2011) Anisotropic critical state theory: role of fabric. J Eng Mech 138:263-275. https://doi. org/10.1061/(ASCE)EM.1943-7889.0000324

21. Dafalias YF, Li XS, Dafalias YF (2004) A constitutive framework for anisotropic sand including non-proportional loading. Géotechnique 54:41-55. https://doi.org/10.1680/geot.54.1.41.36329

22. Gao Z, Zhao J, Li XS, Dafalias YF (2014) A critical state sand plasticity model accounting for fabric evolution. Int J Numer Anal Methods Geomech 38:370-390. https://doi.org/10.1002/nag.2211

23. Gao Z, Zhao J (2015) Constitutive modeling of anisotropic sand behavior in monotonic and cyclic loading. J Eng Mech 141:04015017. https://doi.org/10.1061/(ASCE)EM.1943-7889.0000907

24. Pietruszczak S, Mroz Z (2000) Formulation of anisotropic failure criteria incorporating a microstructure tensor. Comput Geotech 26:105-112. https://doi.org/10.1016/s0266-352x(99)00034-8

25. Pietruszczak S, Mroz Z (2001) On failure criteria for anisotropic cohesive-frictional materials. Int J Numer Anal Methods Geomech 25:509-524. https://doi.org/10.1002/nag.141

26. Lade PV (2007) Modeling failure in cross-anisotropic frictional materials. Int J Solids Struct 44:5146-5162. https://doi. org/10.1016/j.ijsolstr.2006.12.027

27. Lade PV (2008) Failure criterion for cross-anisotropic soils. J Geotech Geoenviron Eng 134:117-124. https://doi. org/10.1061/(asce)1090-0241(2008)134:1(117)

28. Schweiger HF, Wiltafsky C, Scharinger F, Galavi V (2009) A multilaminate framework for modelling induced and inherent anisotropy of soils. Géotechnique 59:87-101. https://doi.org/10.1680/geot.2008.3770

29. Kong Y, Zhao J, Yao Y (2013) A failure criterion for cross-anisotropic soils considering microstructure. Acta Geotech 8:665-673. https://doi.org/10.1007/s11440-012-0202-7

30. Nakai T, Matsuoka H (1983) Shear behavior of sand and clay under three-dimensional stress condition. Soils Found 23:26-42. https://doi.org/10.1248/cpb.37.3229

31. Nakai T, Matsuoka H (1983) Constitutive equation for soils based on the extended concept of "Spatial mobilized plane" and its application to finite element analysis. Soils 23:87-105. https://doi.org/10.1248/cpb.37.3229

32. Rodriguez NM, Lade PV (2013) Effects of principal stress directions and mean normal stress on failure criterion for cross-anisotropic sand. J Eng Mech 139:1592-1601. https://doi.org/10.1061/(asce)em.1943-7889.0000595

33. Zheng J, Hryciw RD (2017) Particulate material fabric characterization by rotational haar wavelet transform. Comput Geotech 88:46-60. https://doi.org/10.1016/j.compgeo.2017.02.021

34. Zheng J, Hryciw RD (2018) Cross-anisotropic fabric of sands by wavelet-based simulation of human cognition. Soils Found 58:1028-1041. https://doi.org/10.1016/j.sandf.2018.06.001

35. Zhang L (2010) Estimating the strength of jointed rock masses. Rock Mech Rock Eng 43:391-402

36. Park C, Tatsuoka F (1994) Anisotropic strength and deformation of sands in plane strain compression. In: The 13th international conference on soil mechanics and foundation engineering, pp 1-4

\section{Publisher's Note}

Springer Nature remains neutral with regard to jurisdictional claims in published maps and institutional affiliations. 